\title{
Role of radiography, MRI and FDG-PET/CT in diagnosing, staging and therapeutical evaluation of patients with multiple myeloma
}

\author{
Susanne Lütje • Jacky W. J. de Rooy • \\ Sandra Croockewit • Emmeline Koedam • \\ Wim J. G. Oyen • Reinier A. Raymakers
}

Received: 28 July 2009 / Accepted: 26 August 2009 / Published online: 18 September 2009

(C) The Author(s) 2009. This article is published with open access at Springerlink.com

\begin{abstract}
Multiple myeloma is a malignant B-cell neoplasm that involves the skeleton in approximately $80 \%$ of the patients. With an average age of 60 years and a 5 -years survival of nearly $45 \%$ Brenner et al. (Blood 111:2516-2520, 35 ) the onset is to be classified as occurring still early in life while the disease can be very aggressive and debilitating. In the last decades, several new imaging techniques were introduced. The aim of this review is to compare the different techniques such as radiographic survey, multidetector computed tomography (MDCT), whole-body magnetic resonance imaging (WB-MRI), fluorodeoxyglucose positron emission tomography- (FDG-PET) with or without computed tomography $(\mathrm{CT})$, and ${ }^{99 \mathrm{~m}} \mathrm{Tc}-\mathrm{methoxyisobutylisonitrile}\left({ }^{99 \mathrm{~m}} \mathrm{Tc}-\right.$ MIBI) scintigraphy. We conclude that both FDG-PET in combination with low-dose CT and whole-body MRI are more sensitive than skeleton $\mathrm{X}$-ray in screening and diagnosing multiple myeloma. WB-MRI allows assessment of bone marrow involvement but cannot detect bone destruction, which might result in overstaging. Moreover, WB-MRI is less suitable in assessing response to therapy
\end{abstract}

\footnotetext{
S. Lütje $(\bowtie) \cdot$ S. Croockewit $\cdot$ R. A. Raymakers $(\bowtie)$

Department of Haematology,

Radboud University Nijmegen Medical Centre,

Nijmegen, Netherlands

e-mail: S.Lutje@nucmed.umcn.nl

e-mail: R.Raymakers@hemat.umcn.nl

J. W. J. de Rooy E. Koedam

Department of Radiology,

Radboud University Nijmegen Medical Centre,

Nijmegen, Netherlands

W. J. G. Oyen

Department of Nuclear Medicine,

Radboud University Nijmegen Medical Centre,

Nijmegen, Netherlands
}

than FDG-PET. The combination of PET with low-dose CT can replace the golden standard, conventional skeletal survey. In the clinical practise, this will result in upstaging, due to the higher sensitivity.

Keywords Multiple myeloma $\cdot$ Radiography $\cdot$ MDCT . WB-MRI $\cdot$ FDG-PET/CT $\cdot{ }^{99 \mathrm{~m}} \mathrm{Tc}-\mathrm{MIBI}$

\section{Introduction}

Multiple myeloma is a neoplasm of B cells which is characterised by bone marrow infiltration and production of monoclonal immunoglobulins [1]. Multiple myeloma accounts for approximately $10 \%$ of the hematologic malignancies and the incidence is increasing, reaching four in every 100,000 per year with a peak during the seventh decade of life [2].

The diagnosis is based on laboratory parameters in combination with bone marrow biopsy or bone marrow aspiration [3] providing information about paraproteinaemia, bone marrow plasma cell infiltration and osteolytic bone destruction. Lytic bone lesions are present in approximately $80 \%$ of patients with a high risk of pathological fractures, hypercalcaemia and bone pain [1].

In staging, treatment evaluation and prognosis of patients with multiple myeloma, detection of osteolytic bone lesions has critical value. Even though new imaging techniques as FDG-PET/CT or WB-MRI have been introduced to assess extent and severity of multiple myeloma, most institutions still use conventional radiographs to evaluate disease stage, progression and therapy response, since this technology had been evaluated in many studies in the past and still is considered to be the golden standard. Moreover, in the Durie and Salmon myeloma staging system (Table 1) 
Table 1 Overview of the original Durie/Salmon staging system $(A)$ and the Durie/Salmon PLUS staging system (B)

\begin{tabular}{|c|c|c|c|c|}
\hline \multicolumn{2}{|l|}{ A: Original system } & \multicolumn{3}{|l|}{ B: Plus system } \\
\hline CRITERIA & $\begin{array}{l}\text { Measured myeloma cell mass in } \\
\text { whole body (myeloma cells in } \\
\text { billions } / \mathrm{m}^{2} \text { ) [35] }\end{array}$ & Classification & Plus & $\begin{array}{l}\text { New imaging MRI and/or } \\
\text { FDG-PET }\end{array}$ \\
\hline \multicolumn{5}{|l|}{ All of the following: } \\
\hline \multicolumn{5}{|l|}{ Haemoglobin value $>10 \mathrm{~g} / \mathrm{dl}$} \\
\hline \multicolumn{5}{|l|}{$\begin{array}{l}\text { Serum calcium value normal or } \\
<10.5 \mathrm{mg} / \mathrm{dl}\end{array}$} \\
\hline \multicolumn{5}{|l|}{$\begin{array}{l}\text { Bone X-ray, normal bone structure } \\
\text { (scale } 0 \text { ), or solitary bone plasma- } \\
\text { cytoma only }\end{array}$} \\
\hline \multicolumn{5}{|c|}{ Low M-component production rates: } \\
\hline \multicolumn{5}{|l|}{ IgG value $<5.0 \mathrm{~g} / \mathrm{dl}$} \\
\hline \multicolumn{5}{|l|}{ IgA value $<3.0 \mathrm{~g} / \mathrm{dl}$} \\
\hline \multicolumn{5}{|c|}{$\begin{array}{l}\text { Urine light chain M-component on } \\
\text { electrophoresis }<4 \mathrm{~g} / 24 \mathrm{~h}\end{array}$} \\
\hline \multicolumn{5}{|l|}{ Stage II (intermediate cell mass) } \\
\hline Fitting neither stage I nor stage III & $600-1,200$ billion & $\begin{array}{l}\text { Stage I A [35] } \\
\text { (Smouldering or } \\
\text { indolent) }\end{array}$ & & $\begin{array}{l}\text { Can have single plasmacytoma } \\
\text { and/or limited disease on } \\
\text { imaging }\end{array}$ \\
\hline Stage III (high cell mass) & $>1,200$ billion & Multiple myeloma & & \\
\hline \multicolumn{5}{|l|}{ One or more of the following: } \\
\hline \multicolumn{2}{|l|}{ Haemoglobin value $<8.5 \mathrm{~g} / \mathrm{dl}$} & & & $<5$ focal lesions \\
\hline \multicolumn{2}{|l|}{ Serum calcium value $>12 \mathrm{mg} / \mathrm{dl}$} & Stage I B [35] & & Mild diffuse disease \\
\hline \multicolumn{2}{|l|}{ Advanced lytic bone lesions (scale 3) } & & & 5-20 focal lesions \\
\hline \multicolumn{2}{|c|}{ High M-component production rates } & Stage II A/B [35] & & Moderate diffuse disease \\
\hline \multicolumn{2}{|l|}{$\mathrm{IgG}$ value $>7.0 \mathrm{~g} / \mathrm{dl}$} & & & 20 focal lesions \\
\hline \multicolumn{2}{|l|}{ IgA value $>5.0 \mathrm{~g} / \mathrm{dl}$} & Stage III A/B [35] & & Severe diffuse disease \\
\hline \multicolumn{5}{|c|}{$\begin{array}{l}\text { Urine light chain M-component on } \\
\text { electrophoresis }>12 \mathrm{~g} / 24 \mathrm{~h}\end{array}$} \\
\hline Sub classification (either $A$ or $B$ ) & A: relatively normal renal function (serum creatinine value) $<2.0 \mathrm{mg} / \mathrm{dl}$ & [35] A & \multicolumn{2}{|c|}{$\begin{array}{l}\text { Serum creatinine }<2.0 \mathrm{mg} / \mathrm{dl} \\
\text { No extramedullary disease }(\mathrm{EMD})\end{array}$} \\
\hline \multicolumn{2}{|c|}{ B: abnormal renal function (serum creatinine value) $>2.0 \mathrm{mg} / \mathrm{dl}$} & [35] B & \multicolumn{2}{|c|}{$\begin{array}{l}\text { Serum creatinine } \geq 2.0 \mathrm{mg} / \mathrm{dl} \\
\text { Extramedullary disease }(\mathrm{EMD})\end{array}$} \\
\hline
\end{tabular}

introduced in 1975 [4], the detection of bone lesions by radiographic survey correlated with measured myeloma cell mass. This staging system has been widely used over the past 30 years.

Unfortunately, despite low costs and wide employment and availability, the use of conventional radiography, especially whole-body surveys, has several limitations.

\section{Radiography}

Conventional radiography

Conventional skeletal survey is used in the initial work-up in patients with multiple myeloma, although the false- negative rate $(30-70 \%)$ is relatively high, leading to significant underestimation in diagnosing and staging of patients with multiple myeloma [5].

Diffuse bone marrow involvement, which may or may not be associated with bone destruction, is not evaluable using conventional radiography. Although the role of early diagnosis and treatment of bone marrow involvement is not yet established, lytic lesions become apparent on conventional radiography when already $30-50 \%$ of the bone mineral density is lost [6]. Early myeloma may thus not reveal observable changes on conventional radiographs.

Moreover, osteopaenia as a result of bone marrow infiltration by multiple myeloma as well as osteoclastactivity induced by this disease cannot be distinguished on conventional radiographs from more common causes 
of osteopaenia, for example senile and postmenopausal osteoporosis [7, 8].

However, radiography is more helpful in detecting trabecular/cortical bone lesions while MRI is more sensitive, particularly in the vertebral bone marrow, to show diffuse or focal bone marrow involvement, which has not or not yet caused destruction of mineralised bone.

Another disadvantage of radiographic technologies is that history and activity status of myeloma cannot be estimated [9].

A further disadvantage of radiography is that varied positions required for radiography films are painful and tiring for patients who are often elderly and disabled due to previous pathological fractures.

\section{Multidetector computed tomography}

Multidetector computed tomography (MDCT) is a widely employed alternative to conventional radiography and is considered as the ideal tool for detection of early bone destruction [9].

Extramedullary lesions can also be detected and the diagnostic sensitivity of CT imaging is superior to that of conventional radiography and reveals more lesions in areas that cannot be accurately visualised by radiography $[10,11]$.

Moreover, it has been shown that CT is superior to conventional radiography in estimating instability of areas with bone lesions and fracture risk, e.g. prior to vertebroplasty [12]. Unfortunately, the radiation dose used in CT is much higher (up to 400 times, Table 2) than the dose used in radiographic survey. Moreover, just as conventional radiographic surveys, $\mathrm{CT}$ is non-specific for evaluation of osteopaenia [13].

For staging of patients with multiple myeloma, evaluation of the whole skeleton is critical. Therefore, whole-body MDCT was introduced.

Table 2 Comparison of typical doses from CT and conventional $\mathrm{X}$-ray examinations [34]

\begin{tabular}{lc}
\hline Diagnostic procedure & Typical effective dose (mSv) \\
\hline Conventional X-ray & \\
Chest (single PA film) & 0.02 \\
Pelvis & 0.7 \\
Abdomen & 1.0 \\
Computed tomography & \\
Chest & 8 \\
Pelvis & 10 \\
Abdomen & 10 \\
\hline
\end{tabular}

MDCT provides faster scanning time and higher $z$ axis resolution than single-slice helical $\mathrm{CT}$, leading to high quality real-time 3-D images [13]. Thus, MDCT is very sensitive in detecting small osteolytic lesions $(<5 \mathrm{~mm})$, especially in the spine [13] and leads to high-resolution imaging of cortical and trabecular bone within an acquisition time of $1 \mathrm{~min}$ [5].

Another advantage is that, due to increased accuracy of multiplanar acquisition technique, distinction of bony structures and soft tissues is possible to a much higher level avoiding artefacts such as shadows that could lead to false-positive results [10].

Using MDCT, the effects of tumour infiltration can be visualised. However, it takes some time before osteoclastic activity of myeloma cells leads to bone destruction. Therefore, MDCT will show no abnormalities in early focal marrow infiltration [5].

In diffuse bone marrow infiltration, the false-negative rate is relatively high. This may be due to the fact that diffuse infiltration leads to interstitial infiltration of bone marrow which is not necessarily associated with destruction of trabecular or cortical bone [5]. One of the most important drawbacks in applying whole-body MDCT is the highradiation dose in access of $35 \mathrm{mSv}$ [10].

To overcome this problem, whole-body low-dose computed tomography (LDCT) was introduced.

\section{Whole-body low-dose MDCT}

Whole-body LDCT operates at lower radiation doses and is superior to skeletal X-ray in detecting osteolytic lesions and in determining overall stage of multiple myeloma (restaging) [10], and the level of diagnostic confidence is much higher when interpreting whole-body LDCT (at lower doses than previously reported) than conventional radiography. In addition, further reductions in radiation doses are feasible.

Furthermore, additional findings detectable on wholebody LDCT, e.g. additional osteolytic lesions, emphysema, lymphadenopathy or hepatosplenomegaly cannot be detected on conventional skeletal survey [10].

Whole-body LDCT is superior to whole-body magnetic resonance imaging (WB-MRI) in detecting residual osteolytic abnormalities which are mostly not seen on WB-MRI.

The sharp algorithm used to optimise osseous structure assessment implies that the diagnosis of visceral pathology is limited but this problem could be overcome by the use of a special soft tissue algorithm [10].

Furthermore, iodine-containing contrast agents, relatively contraindicated for patients with Bence-Jones proteinuria because of the risk of cast nephropathy and renal failure, are not needed for skeletal CT [14]. 


\section{Magnetic resonance imaging}

Whole-body MRI

Using magnetic resonance imaging (MRI), bone marrow involvement, loss of fatty bone marrow components and replacement by pathologic cells can be evaluated [15].

Moreover, MRI has prognostic significance; the number of lesions on MRI correlates very well with treatment outcome and overall survival of patients with multiple myeloma [16]. However, the pattern of marrow infiltration (focal or diffuse) does not necessarily equate with a need for immediate therapy.

Unfortunately, this technology also has some disadvantages such as prolonged acquisition time (about $45 \mathrm{~min}$ ), high costs and limiting patient factors such as claustrophobia or metal devices in their body [1,9].

The difficulty of radiography to distinguish between treated bone marrow lesions and viable neoplastic tissue (active and fibrotic lesions) is encountered in MRI as well $[1,17]$. This results in limited capacity to monitor the response to therapy because it takes 9-12 months for lesions evident on MRI to resolve and be clearly indicative of response [9].

Although bone marrow infiltration of ribs, spine (most importantly), pelvis and sternum [7, 18] and extensive disease [19] can be visualised and MRI is more sensitive and specific than radiological skeletal surveys in detecting disease [19], it is not able to explore specific bones [1, 18] such as the skull, clavicle or ribs. These bones cannot be investigated reliably because of respiratory movements or because they could be too small to be located in one of the MRI slices leading to false-negative results and understaging of multiple myeloma patients.

To overcome the disadvantages of a partial field of view, whole-body MRI (WB-MRI) was introduced which provides several benefits.

With this technique, the patient's whole body can be scanned. Unfortunately, WB-MRI is not yet widely employed and less available [1].

WB-MRI has been reported to be particularly useful in early smouldering MM likely to be less FDG avid [10] and it is most common to scan the spine and pelvis for screening purposes [9] because of the more detailed assessment of bone marrow infiltration pattern.

As compared to whole-body MDCT, WB-MRI has superior sensitivity for both focal and diffuse pattern of bone marrow involvement and will result in upstaging of multiple myeloma. Moreover, the detection rate of extensive disease and the rate of bone manifestations using WBMRI are higher than whole-body MDCT [5, 10].

WB-MRI also detects more lesions than whole-body LDCT [10].
It has been recommended to apply WB-MRI in addition to standard skeletal survey for several reasons [18]: First, it allows detection of focal lesions before osteolysis can be visualised on a bone survey. Second, detection and staging of nonsecretory and macrofocal myeloma and detecting of nonsecretory or macrofocal relapse are possible. Relapse on MRI can be diagnosed when an increase in size/number of focal lesions or development of abnormal diffuse bone marrow becomes present [18].

Dynamic contrast-enhanced MRI

To detect and monitor changes in bone marrow microcirculation as a result of myeloma-induced angiogenesis and blood vessel permeability, dynamic contrast-enhanced MRI was introduced (DCE-MRI) [20].

This non-invasive technique allows evaluation of the microcirculation in malignant tissues.

It has been reported that DCE-MRI-derived microcirculation variable amplitude $A$ is proportional to the relative signal enhancement. This signal was significantly increased in patients with multiple myeloma, correlated with osteolytic bone involvement [20] and was identified as an adverse prognostic variable for event-free survival in progressive myeloma. A high amplitude $A$, thus an increased microcirculation, points towards a low event-free survival [20]. Amplitude $A$ as an adverse prognostic variable showed a trend for overall survival as well.

DCE-MRI also correlates with local complications and degree of bone destruction in multiple myeloma [20].

The most important advantage of this technique is the possibility to identify patients who could profit from therapeutics targeting the microcirculation with antiangiogenic drugs such as bevacizumab, a monoclonal antibody inhibiting vascular endothelial growth factor (VEGF) [20].

Furthermore, it has been shown that DCE-MRI could complement standard MRI and may be superior in determining disease activity and response to therapy [20, 21].

Besides many advantages of the described techniques, determining history and activity status of bone lesions in multiple myeloma cannot be assessed.

\section{FDG-PET}

Fluorodeoxyglucose is an analogue of glucose which is labelled with the positron-emitting radionuclide ${ }^{18} \mathrm{~F}$. Fluorodeoxyglucose is taken up and phosphorylised by metabolically active cells which do not further metabolise it but store it after uptake. This results in an accumulation of this molecule that can be visualised with PET.

Tumour cells can be imaged with this technique due to their high metabolism rate and the resulting high glucose 
demand. This allows tumour cells to be distinguished from normal cells.

\section{Conventional FDG-PET}

One of the most important advantages of FDG-PET is the ability to scan the whole body in reasonable time frame [9] and in a single procedure [17].

Furthermore, FDG-PET can detect bone marrow/ myelomatous involvement with high sensitivity and specificity. FDG-PET can detect and distinguish between intramedullary and extramedullary lesions in a single examination in patients with multiple myeloma [17]. Unfortunately, very small lesions (subcentimeter size) may not be detected as a certain minimum tumour burden is required for delineation by FDG-PET [17].

It has been reported that FDG-PET for the assessment of disease extent at the time of initial diagnosis resulted in upstaging of disease and thus more aggressive therapy [17].

The most significant advantageous feature of FDG-PET is probably being a functional imaging technique by its ability to distinguish between active myeloma (FDGpositive) and monoclonal gammopathy of undetermined significance (MGUS) or smouldering disease.

MGUS is defined by the presence of a serum monoclonal (M) protein $<3 \mathrm{~g} / \mathrm{dL}$, bone marrow plasma cells $<10 \%$, and absence of anaemia, hypocalcaemia, lytic bone lesions, or renal failure attributable to the plasma cell proliferative disorder [22].

Smouldering disease is defined by serum $M$ protein $\geq 3 \mathrm{~g} / \mathrm{dL}$ or bone marrow plasma cells $\geq 10 \%$, plus absence of anaemia, hypocalcaemia, lytic bone lesions, or renal failure attributable to the plasma cell proliferative disorder [22].

Usually, MGUS and low-level smouldering disease are negative on FDG-PET [9] with MGUS showing neither diffuse marrow uptake nor areas of focal disease in marrow sites [23].

Active myeloma is FDG-positive for focal and diffuse abnormalities and FDG uptake decreases rapidly (within hours) after effective therapy. Persistent FDG-PET positivity correlates with earlier relapse [9].

As FDG-PET also detects inflammatory and infectious complications, it can be useful for diagnosis of complications of therapy, such as vascular infections as septic thrombophlebitis, infections of implantable catheters and severe neutropaenia which can lead to modifications of the therapeutic strategy [24].

However, it has to be taken into account that infection and inflammation (also after radiotherapy or surgery) may result in false-positive interpretation for active multiple myeloma [17].

\section{FDG-PET combined with CT}

To overcome the low spatial resolution of FDG-PET, integrated FDG-PET/CT has become the standard methodology. FDG-PET/CT combines the high contrast resolution (sensitivity) of PET with high spatial resolution (anatomy) of $\mathrm{CT}$, which is more sensitive than whole-body radiography for detection of small lytic bone lesions and has similar sensitivity as MRI in detecting diffuse disease in spine and pelvis. Furthermore, FDG-PET combined with CT performed better than ${ }^{99 m}$ Tc-MIBI and MRI in detection of focal lesions [25]. However, an infiltrative pattern in the spine can be depicted more adequately with MRI than with FDG-PET/CT [1].

It has been reported that FDG-PET/CT can significantly contribute to an accurate whole-body evaluation of multiple myeloma patients while MRI should be used especially for evaluation of bone marrow involvement [25], because it allows visualisation of the bone content with a high spatial resolution [25, 26]

Durie et al. [9] conclude in their paper that FDG-PET combined with CT scanning would provide the ideal screening technology for multiple myeloma since FDGPET uptake indicates active myeloma and CT shows bone destruction [9, 27].

\section{${ }^{99}$ Tc-MIBI}

${ }^{99 \mathrm{~m}}$ Tc-labelled hexakis-2-methoxyisobutylisonitrile is a radiopharmaceutical which accumulates in tissues with high cellular density and mitochondrial activation as it can be found in malignant tissues. ${ }^{99 \mathrm{~m}} \mathrm{Tc}-\mathrm{MIBI}$ imaging reflects myeloma disease activity in bone marrow with very high sensitivity and specificity [28, 29]. Additionally, bone marrow biopsy results linearly correlate with bone marrow uptake of ${ }^{99 \mathrm{~m}} \mathrm{Tc}-\mathrm{MIBI}$ and ${ }^{99 \mathrm{~m}} \mathrm{Tc}-\mathrm{MIBI}$ was reported to be localised inside the plasma cells infiltrating the bone marrow [8].

In MGUS, ${ }^{99 \mathrm{~m}} \mathrm{Tc}-\mathrm{MIBI}$ is always negative [8] so it could be useful in discrimination between MGUS and multiple myeloma.

Using ${ }^{99 \mathrm{~m}}$ Tc-MIBI, it is possible to scan soft and skeletal lesions and the overall sensitivity is approximately $92 \%$ and it specificity is $96 \%$ [30]. ${ }^{99 \mathrm{~m}} \mathrm{Tc}-\mathrm{MIBI}$ is superior compared with FDG-PET/CT for the visualisation of diffuse disease and despite its limited capacity in detecting focal lesions this technique may be an alternative option when PET is not available.

In comparison to MRI, it has been found that ${ }^{99 \mathrm{~m}} \mathrm{Tc}$ MIBI underestimates the extent of bone marrow infiltration in the spine, especially in patients with low disease stage [31]. 


\section{Durie/Salmon PLUS staging system}

Because early myeloma may reveal no abnormalities on conventional radiography, Durie et al. [9] introduced an update of their original staging system published in 2005 . The new system, named Durie/Salmon PLUS staging system, integrates new imaging techniques into anatomic and functional myeloma staging (Table 1).

The new system overcomes two limitations: on the one hand, the classification of early disease detected only by $\mathrm{PET} / \mathrm{CT}$ and/or MRI becomes better since patients with definite active myeloma are distinguished from those with MGUS or smouldering disease and on the other hand, the discrimination of patients with stage II and III disease will be improved.

In clinical studies, the $\mathrm{CRAB}$ criteria are used to establish multiple myeloma related organ dysfunction: hypercalcaemia, renal disease, anaemia and osteolytic bone lesions. In these criteria multiple osteolytic bone lesions is an item, as well as osteoporosis or a solitary plasmocytoma given more than $30 \%$ bone marrow plasma cells.

\section{New developments}

Although many new technologies were introduced during the past decennia, all have special impediments.

A relatively new technology is diffusion-weighted wholebody imaging with background body signal suppression
(DWIBS). With this technique, altered diffusion in cells and tissues can be detected as it may appear in malignant tumours bearing high cellular density with more cellular membranes per volume unit, impeding the mobility of water molecules and restricting diffusion [32].

On the other hand, diffusion may be increased in tumours as well, due to necrotic loss of cell membrane integrity.

There are several potential applications of DWIBS in oncology, for instance in staging, monitoring response to therapy or detection of tumour persistence or recurrence. Even though these features could complement conventional technologies, much research is still necessary.

Another imaging technique for multiple myeloma is the recently developed PET tracer 3'-fluoro-3'-deoxy-Lthymidine $\left({ }^{18} \mathrm{~F}\right.$-FLT). ${ }^{18} \mathrm{~F}$-FLT is taken up into cells in relation to the rate of DNA synthesis and with higher proliferation rates as it is common in many cancers, ${ }^{18} \mathrm{~F}$ FLT increases in the cells [33]. Therefore, ${ }^{18}$ F-FLT PET might visualise the high cycling activity of haematopoietic cells in the bone marrow compartment and may be helpful to distinguish separate haematologic disorders [33] (Table 3).

\section{Discussion}

Currently, the baseline diagnostic evaluation to detect osteolytic bone lesions comprises conventional radiography. In case of negative results while symptoms of the disease are present, CT or MRI is usually performed.

Table 3 Overview of the different technologies

\begin{tabular}{|c|c|c|c|c|c|c|c|c|c|}
\hline & X-ray & CT & MDCT & LDCT & MRI & WB-MRI & DCE-MRI & $\mathrm{PET} / \mathrm{CT}$ & Tc-MIBI \\
\hline Costs (- low, + high) & - & + & $+/-$ & $+/-$ & ++ & ++ & ++ & +++ & ++ \\
\hline Radiation (mSv) & + & ++ & +++ & ++ & - & - & - & + & - \\
\hline Acquisition time ( - low, + high $)$ & - & + & - & - & ++ & +++ & ++ & ++ & ++ \\
\hline Patient experience & +++ & $+/-$ & $++/-$ & $++/-$ & - & -- & - & - & \\
\hline Sensitivity & $+/-$ & + & ++ & + & ++ & +++ & + & +++ & ++ \\
\hline Availability & +++ & ++ & + & + & + & - & - & + & - \\
\hline Spatial resolution & + & ++ & ++ & ++ & ++ & +++ & + & ++ & + \\
\hline Understaging ( - low risk, + high risk) & + & + & + & + & $+/-$ & - & & - & $+/-$ \\
\hline Early diagnosis & - & - & - & - & + & + & + & +++ & ++ \\
\hline Bone marrow & - & - & $+/-$ & - & ++ & ++ & ++ & + & + \\
\hline Osteolytic lesions & $+/-$ & ++ & ++ & ++ & + & + & + & ++ & - \\
\hline Age and activity status of MM & - & - & - & - & - & - & $+/-$ & ++ & + \\
\hline Response to therapy & - & - & - & - & $+/-$ & $+/-$ & $++/-$ & ++ & + \\
\hline Bone marrow microcirculation & - & - & - & - & - & - & + & - & - \\
\hline Subcentimeter lesions & $+/-$ & + & $++<5 \mathrm{~mm}$ & + & + & + & & + & + \\
\hline Separation MGUS and MM & - & - & - & - & & & & ++ & + \\
\hline Focal lesions & + & + & + & + & ++ & ++ & - & +++ & $+/++$ \\
\hline Diffuse lesions & + & + & + & + & ++ & ++ & - & ++ & +++ \\
\hline
\end{tabular}


Despite low costs and wide availability, conventional radiographic surveys have profound disadvantages such as relatively high false-negative rates and lack of bone marrow evaluation which make this technology less suitable for early diagnosing/staging/evaluating multiple myeloma.

CT overcomes problems as low anatomic resolution and the newly developed whole-body technology allows examination of the whole body to diagnose spread of the disease in the periphery. Nonetheless, converse to conventional radiography, the radiation dose is much higher.

Therefore, whole-body LDCT was introduced. Despite lower radiation doses, given a high-enough resolution of the CT scan the sensitivity for detecting osteolytic foci and determining overall stage is still much higher than in simple radiographic technologies [10].

In our view, the most sensitive technique to evaluate osteolytic bone lesions in multiple myeloma is PET/LDCT. The addition of PET to the low-dose CT will enhance the sensitivity for detection of rib lesions and extramedullary lesions. Moreover, as compared to MRI and ${ }^{99 \mathrm{~m}} \mathrm{Tc}-\mathrm{MIBI}$, hybrid FDG-PET/LDCT performed better in detection of focal lesions. Furthermore, FDG-PET offers great opportunities because of the capacity to differentiate between bone marrow lesions and viable neoplastic tissue, due to the ability to visualise highly energy-consuming cells such as tumour cells.

Thus, introduction of these hybrid FDG-PET/LDCT scanners facilitates the determination of the accurate anatomical position of active disease as detected by PET with an acceptable radiation dose.

Because it has been shown that MRI is more sensitive than FDG-PET/LDCT in detecting infiltrative pattern in the spine [1], careful evaluation of multiple myeloma bone disease can include WB-MRI in case the patient has complaint with a negative FDG-PET/LDCT. However, whereas WB-MRI is very sensitive in detecting bone marrow involvement, the major reason to treat patients with myeloma is osteolytic disease, which is not detected by MRI.

Also regarding to follow-up, PET/LDCT is the most sensitive technique to evaluate result of treatment. In that respect, it is more sensitive than MRI to differentiate between treated bone marrow lesions and viable neoplastic tissues.

We conclude that FDG-PET/LDCT can replace the golden standard, conventional radiography. We have to realise that due to the higher sensitivity, patients will be upstaged and treatment in this group of patients will start in an earlier phase of the disease. However, from a patient's point of view and given the more effective treatment combinations available nowadays with more complete remissions in first-line treatment, skeletal damage can be prevented at least in some of the patients.
In clinical studies, it may be considered to perform conventional radiography next to FDG-PET/LDCT in order to compare the treatment results with historical data.

Open Access This article is distributed under the terms of the Creative Commons Attribution Noncommercial License which permits any noncommercial use, distribution, and reproduction in any medium, provided the original author(s) and source are credited.

\section{References}

1. Nanni C, Zamagni E, Farsad M, Castellucci P, Tosi P, Cangini D, Salizzoni E, Canini R, Cavo M, Fanti S (2006) Role of ${ }^{18}$ F-FDG $\mathrm{PET} / \mathrm{CT}$ in the assessment of bone involvement in newly diagnosed multiple myeloma: preliminary results. Eur J Nucl Med Mol Imaging 33:525-531

2. Landis SH, Murray T, Bolden S, Wingo PA (1998) Cancer Statistics, 1998. CA Cancer J Clin 48:6-29

3. Rajkumar SV, Kyle RA (2005) Multiple myeloma: diagnosis and treatment. Mayo Clin Proc 80:1371-1382

4. Durie BGM, Salmon SE (1975) A clinical staging system for multiple myeloma. Cancer 36:842-854

5. Baur-Melnyk A, Buhmann S, Becker C, Oswald Schoenberg S, Lang N, Bartl R, Ferdinand Reiser M (2008) Whole-body MRI versus whole-body MDCT for staging of multiple myeloma. AJR 190:1097

6. Baur-Melnyk A, Reiser M (2004) Staging des multiplen myeloms mit der MRT: vergleich zur MSCT und zur konventionellen Röntgendiagnostik. Radiologe 44:874-881

7. Dinter DJ, Neff WK, Klaus J, Böhm C, Hastka J, Weiss C, Schoenberg SO, Metzgeroth G (2009) Comparison of whole-body MR imaging and conventional X-ray examination in patients with multiple myeloma and implications for therapy. Ann Hematol $88: 457-464$

8. Dimopoulos M, Terpos E, Comenzo RL, Tosi P, Beksac M, Sezer O, Siegel D, Lokhorst H, Kumar S, Rajkumar SV, Niesvizky R, Moulopoulos LA, Durie BGM (2009) International myeloma working group consensus statement and guidelines regarding the current role of imaging techniques in the diagnosis and monitoring of multiple myeloma. Leukemia. doi:10.1038/leu.2009.89

9. Durie BGM (2006) The role of anatomic and functional staging in myeloma: description of Durie/Salmon plus staging system. Eur J Cancer 42:1539-1543

10. Gleeson TG, Moriarty J, Shortt CP, Gleeson JP, Fitzpatrick P, Byrne B, McHugh J, O'Connell M, O'Gorman P, Eustace SJ (2009) Accuracy of whole-body low-dose multidetector CT (WBLDCT) versus skeletal survey in the detection of myelomatous lesions, and correlation of disease distribution with whole-body MRI. Skeletal Radiol 38:225-236

11. Mahnken AH, Wildberger JE, Gehbauer G, Schmitz-Rode T, Blaum M, Fabry U, Günther RW (2002) Multidetector CT of the spine in multiple myeloma: comparison with MR imaging and radiography. AJR 178:1429-1436

12. Horger M, Claussen D, Bross-Bach $\mathrm{U}$, Vonthein R, Trabold T, Heuschmid M, Pfannenberg C (2005) Whole-body low-dose multidetector row-CT in the diagnosis of multiple myeloma: an alternative to conventional radiography. Eur J Radiol 54:289-297

13. Hur J, Yoon CS, Ryu YH, Yun MJ, Suh JS (2007) Efficacy of multidetector row computed tomography of the spine in patients with multiple myeloma: comparison with magnetic resonance imaging and fluorodeoxyglucose-positron emission tomography. J Comput Assist Tomogr 31:342-347 
14. Delorme S, Baur-Melnyk A (2009) Imaging in multiple myeloma. Eur J Radiol 70:401-408

15. Baur A, Bartl R, Pellengahr C, Baltin V, Reiser M (2004) Neovascularization of bone marrow in patients with diffuse multiple myeloma: a correlative study of magnetic resonance imaging and histologic findings. Cancer 101:2599-2604

16. Walker R, Jones-Jackson L et al (2004) Diagnostic imaging of multiple myeloma- FDG PET and MRI complementary for tracking short vs long term tumour response. Blood 104(11):217a

17. Bredella MA, Steinbach L, Caputo G (2004) Value of FDG PET in the assessment of patients with multiple myeloma. American Roentgen Ray Society 184:1199-1204

18. Walker R, Barlogie B, Haessler J, Tricot G, Anaissie E, Shaughnessy JD, Epstein J, Hemert R, Erdem E, Hoering A, Crowley J, Ferris E, Hollmig K, Rhee F, Zangari M, PinedaRoman M, Mohiuddin A, Yaccoby S, Sawyer J, Angtuaco EJ (2007) Magnetic resonance imaging in multiple myeloma: diagnostic and clinical implications. J Clin Oncol 25:1121-1128

19. Ghanem N, Lohrmann C, Engelhardt M, Pache G, Uhl M, Saueressig U, Kotter E, Langer M (2006) Whole-body MRI in the detection of bone marrow infiltration in patients with plasma cell neoplasms in comparison to the radiological skeletal survey. Eur Radiol 16:1005-1014

20. Hillengass J, Wasser K, Delorme S, Kiessling F, Zechmann C, Benner A, Kauczor HU, Ho AD, Goldschmidt H, Moehler TM (2007) Lumbar bone marrow microcirculation measurements from dynamic contrast-enhanced magnetic resonance imaging is a predictor of event-free survival in progressive multiple myeloma. Clin Cancer Res 13:475

21. Moehler TM, Hawighorst H, Neben K, Egerer G, Hillengass J, Max R, Benner A, Ho AD, vKaick G, Goldschmidt H (2001) Bone marrow microcirculation analysis in multiple myeloma by contrast-enhanced dynamic magnetic resonance imaging. Int J Cancer 93:862-868

22. Kyle A et al (2003) Criteria for the classification of monoclonal gammopathies, multiple myeloma and related disorders: a report of the International Myeloma Working Group. Br J Haematol 121:749-757

23. Durie BGM, Waxman AD, D'Agnolo A, Williams CM (2002) Whole-body 18F-FDG PET identifies high-risk myeloma. J Nucl Med 43:1457-1463

24. Mahfouz T, Miceli MH, Saghafifar F, Stroud S, Jones-Jackson L, Walker R, Grazziutti ML, Purnell G, Fassas A, Tricot G, Barlogie $\mathrm{B}$, Anaissie E (2005) ${ }^{18} \mathrm{~F}$-Fluorodeoxyglucose positron emission tomography contributes to the diagnosis and management of infections in patients with multiple myeloma: a study of 165 infectious episodes. J Clin Oncol 23:7857-7863
25. Fonti R, Salvatore B, Quarantelli M, Sirignano C, Segreto S, Petruzziello F, Catalano L, Liuzzi R, Rotoli B, DelVecchio S, Pace L, Salvatore M (2008) ${ }^{18} \mathrm{~F}-\mathrm{FDG}$ PET/CT, ${ }^{99 \mathrm{~m}} \mathrm{Tc}-\mathrm{MIBI}$, and MRI in evaluation of patients with multiple myeloma. J Nucl Med 49:195-200

26. Zamagni E, Nanni C, Patriarca F, Englaro E, Castellucci P, Geatti O, Tosi P, Tacchetti P, Cangini D, Perrone G, Ceccolini M, Brioli A, Buttignol S, Fanin R, Salizzoni E, Baccarani M, Fanti S, Cavo $\mathrm{M}$ (2007) A prospective comparision of ${ }^{18} \mathrm{~F}$-fluorodeoxyglucose positron emission tomography-computed tomography, magnetic resonance imaging and whole-body planar radiographs in the assessment of bone disease in newly diagnosed multiple myeloma. Haematologica 92:50-55

27. Antoch G, Vogt FM, Freudenberg LS, Nazaradeh F, Goehde SC, Barkhausen J, Dahmen G, Bockisch A, Debatin JF, Ruehm SG (2003) Whole-body dual-modality PET/CT and whole-body MRI for tumour staging in oncology. JAMA 290:3199-206

28. Balleari E, Villa G, Garre S, Ghirlanda P, Agnese G, Carletto M, Clavio M, Ferrando F, Gobbi M, Mariani G, Ghio R (2001) Technetium-99 m-sestaMIBI scintigraphy in multiple myeloma and related gammopathies: a useful tool for the identification and follow-up of myeloma bone disease. Haematologica 86:78-84

29. Tirovola EB, Biassoni L, Britton KE, Kaleva N, Kouykin V, Malpas JS (1996) The use of 99 m-Tc-MIBI scanning in multiple myeloma. Br J Cancer 74:1815-1820

30. Villa G, Balleari E, Carletto M, Grosso M, Clavio M, Piccardo A, Rebella L, Tommasi L, Morbelli S, Peschiera F, Gobbi M, Ghio R (2005) Staging and therapy monitoring of multiple myeloma by 99mTc-sestamibi scintigraphy: a five year single center experience. J Exp Clin Cancer Res 24:355-361

31. Mirzaei S, Filipits M, Keck A, Bergmayer W, Knoll P, Koehn H, Ludwig H, Pecherstorfer M (2003) Comparison of Technetium$99 \mathrm{~m}-\mathrm{MIBI}$ imaging with MRI for detection of spine involvement in patients with multiple myeloma. BMC Nucl Med 3:2

32. Kwee TC, Takahara T, Ochiai R, Nievelstein RAJ, Luijten PR (2008) Diffusion-weighted whole-body imaging with background body signal suppression (DWIBS): features and potential applications in oncology. Eur Radiol 18:1937-1952

33. Agool A, Schot BW, Jager PL, Vellenga E (2006) 18F-FLT PET in hematologic disorders: a novel technique to analyze the bone marrow compartment. J Nucl Med 47:1592-1598

34. Valentin J (2000) How high are the doses? Annals of the ICRP 30:19-24

35. Brenner H, Gondos A, Pulte D (2008) Recent major improvement in long-term survival of younger patients with multiple myeloma. Blood 111:2516-2520 